\title{
A TRANSDISCIPLINARIDADE DA ÁGUA NA LÓGICA DO TERCEIRO INCLUÍDO
}

\author{
TRANSDISCIPLINARIEDAD DEL AGUA EN LA LÓGICA DEL TERCER \\ INCLUSO
}

\section{THE TRANSDISCIPLINARITY WATER IN THE LOGIC OF THIRD INCLUDED}

\author{
Ana Isabel Pereira CARDOSO ${ }^{1}$ \\ Teresinha Maria GONÇALVES ${ }^{2}$
}

\begin{abstract}
RESUMO: A água, fundamental para a vida, é direito e responsabilidade de todos e o acesso de todos à água potável é o grande desafio, assim este artigo tem como objetivo estabelecer relações entre a lógica do terceiro incluído, um dos pilares da transdisciplinaridade, contribuindo para a compreensão e o comprometimento do sujeito dependente, na conservação e preservação da água. Para tanto fez-se necessário a análise das literaturas sobre a água e a transdisciplinaridade em livros, periódicos e artigos; e posteriormente relacionar conceitos e reelaborar teorias, percebendo a transdisciplinaridade como característica inerente a ela, e a educação como foco na formação e informação do cidadão, onde os saberes são elaborados nos diversos contextos de realidades e compreensão do mundo, sendo o usuário o terceiro incluído, diante das relações socioambientais com a água, isto é, o elemento integrador atuante nas questões políticas e ambientais da atualidade que afetam a vida sobre a Terra.
\end{abstract}

Palavras chave: Ambiente, Complexidade, Realidades.

RESUMEN: El agua, fundamental para la vida, es un derecho, una responsabilidad de todos y, el acceso de todos al agua potable, es el gran desafío. Asi este artículo tiene por objetivo establecer relaciones entre la lógica del tercero incluido, uno de los pilares de la transdisciplinaridad con la contribución y el compromiso del sujeto dependiente, en la conservación y preservación del agua, por lo tanto se hace necesario el análisis de las literaturas sobre agua y la transdisciplinaridad en libros periódicos y artículos; y posteriormente relacionar conceptos y reelaborar teorías entendiendo la transdisciplinaridad como característica inherente a ella, y la educación como foco en la formación e información del ciudadano, donde los conocimientos son elaborados en los diversos contextos de realidades y comprensión del mundo, siendo el usuario o tercero incluido, ante las relaciones

\footnotetext{
${ }^{1}$ Professora de Educação Física, Fisioterapeuta e aluna do curso de Ciências Ambientais da Universidade do Extremo Sul Catarinense - UNESC de Criciúma SC. Grupo de Pesquisa em Educação Física GPEF/UNIBAVE anaisabbel@gmail.com

${ }^{2}$ Mestre em Psicologia Social e Doutora em Interdisciplinar em Meio Ambiente e Desenvolvimento Urbano. Docente do Mestrado em Ciências Ambientais, dos cursos de Psicologia e Arquitetura/Urbanismo, coordena o laboratório de Pesquisa em Meio Ambiente e espaço Urbano e Psicologia Ambiental da Universidade do Extremo Sul Catarinense - UNESC de Criciúma - SC. tmg@unesc.net
} 
socioambientales con el agua, este es el elemento integrador actuante en las cuestiones políticas y ambientales de la actualidad que afectan a la vida sobre la Tierra.

Palabras clave: Ambiente, Complejidad, Realidades.

\begin{abstract}
Water, which is vital to life, is everyone's right and responsibility, and universal access to clean water is the big challenge. This paper aims to establish relations between the logic of the third included, one of the pillars of transdisciplinarity, contributing for comprehension and commitment of the dependent subject, on conservation and preservation of water, for both are necessary to analyze the literature about water and transdisciplinarity in books, journals and articles; and subsequently to relate concepts and rework theories. Transdisciplinarity was percieved as a characteristic inherent in it, and education focused on shaping and informing the citizens, where knowledge is developed in different contexts and realities of understanding the world, being the third included the user, in front of the socio-environmental relations with water, i. e. the active integrating element in political and environmental issues of the present that affect life on Earth.
\end{abstract}

Keywords: Environment, Complexity, Realities.

\title{
INTRODUÇÃO
}

O elemento principal da apropriação humana da natureza, para manutenção da vida é a água, porém a incapacidade em lidar com o produto final de tal apropriação, assim como os consequentes problemas socioambientais, evidenciam a complexidade e os níveis de realidade da relação do sujeito com a água.

O reconhecimento da água como patrimônio da humanidade, é dependente do cuidado, por parte de cada usuário, comprometido com o ambiente e a vida sobre a Terra, essencial para a cadeia vital, a água é direito e responsabilidade de todos, pois a própria sobrevivência e manifestação humana produzem situações de risco à integridade do ciclo hidrológico comprometendo e dificultando o processo para torna-la potável. O sujeito dependente é o agente de preservação, na figura do terceiro incluído, com atitudes para o melhor cuidado, responsabilidade e consciência das consequências do próprio uso. $\mathrm{O}$ comprometimento do usuário pagador, poluidor torna-se imprescindível para dar conta destas questões ambientais que envolvem a água. A demanda pela água é crescente e a complexidade das relações humanas com a água exige maior envolvimento, com percepções para além do simples uso. A visão transdisciplinar, dos conflitos ambientais percebidos de forma integral, como nova abordagem perceptiva torna-se instrumento de análise e reflexão, reelaborando 
novas práticas sustentáveis, com gradual mudança de atitude, na interdependência do sujeito com a natureza, sendo o usuário dependente, o sujeito participativo e corresponsável contribuindo com ideias e soluções, como o terceiro incluído, com responsabilidade na preservação e conservação em benefício próprio.

Todo o simbolismo que envolve as relações com a água, cria laços de afetividade e interesse à causa, percebendo a dependência para a vida, possibilita dar sentido ao movimento de conservação, preservação e proteção. A água confunde poder e vulnerabilidade, na natureza, nos remete ao belo e ao sentimental. A água o solvente universal, tem no poder de dissolver infinidade de substâncias, a característica mais comprometedora, pois incorpora todos os tipos de contaminantes e poluentes resultantes das manifestações humanas.

\section{Simbologia da Água}

A água, pelas características e propriedades, está simbolicamente relacionada às emoções profundas, à sentimentos inconscientes, e ao psiquismo. Reporta-nos à receptividade, à captação, à sensibilidade, à empatia e à vulnerabilidade, porém sabemos da força quando canalizada, protegida e preservada, proporcionando vida, percepção e sintonia com outras dimensões.

Chamar a atenção para as questões da água implica em conhecer os significados, criar laços de afetividade e interesse às causas relacionadas a ela, isto é, perceber a interdependência tão abrangente deste elemento com a manutenção da vida na Terra. A sensibilização é de fundamental importância, pois ela despertará o interesse possibilitando o movimento de conservação, preservação e proteção. Só cuida quem tem interesse.

As características físicas e químicas da água, o solvente universal, lhe conferem capacidades de combinação e assimilação à substâncias diversas, ilustrando assim a combinação de poderes conforme refere Bachelard,

Em especial, a água é o elemento mais favorável para ilustrar os temas de combinação de poderes. Ela assimila tantas substâncias! Traz para si tantas essências! Recebe com igual facilidade as matérias contrárias, o açúcar e o sal, Impregna-se de todas as cores, de todos os sabores, de todos os cheiros. Compreende-se, pois, que o fenômeno da dissolução dos sólidos na água seja um dos principais fenômenos dessa química ingênua que continua a ser a química do senso comum e que, com um pouco de sonho é a química dos poetas (BACHELARD, 1998). 
O uso e a conservação da água são resultados da evolução histórica cultural humana, com todo o legado simbólico, a sensibilização como bem patrimonial comum, torna segundo Petrella, (2002. p. 128) "O acesso à água e a obrigação de conservá-la para o objetivo de sobrevivência pertencem à humanidade coletivamente; não podem ser objetos de apropriação individual privada".

Apesar do paradoxo de a água nunca realmente ser desperdiçada, as práticas ambientais de destruições das matas ciliares, dos mananciais; a poluição dos grandes acúmulos de água sobre a superfície terrestre (corpos de água); o crescente e contínuo aumento na demanda em diversas áreas da ação humana, dificulta e onera os empreendimentos relacionados à preservação e distribuição, com processos cada vez mais caros e lentos para tornar a água potável.

A sensibilização é possível, diante da compreensão histórica e cultural do sujeito envolvido, isto é, por meio dos sentimentos de direito, propriedade e pertencimento para com a água, formando laços de afetividade e interesse expressados e manifestados em ações de proteção e preservação. O cuidado com a água na atualidade está longe de ser suficiente para garantir a distribuição em quantidade e qualidade para as atuais gerações, quiçá a garantia às gerações futuras.

A percepção, por parte do sujeito, da importância da água para a cadeia vital, isto é, para a subsistência humana, possibilita a mudança das atitudes e hábitos para o melhor uso e aproveitamento, contribuindo para a preservação e o acesso de todos à água potável. O elemento água, “[...] constitui nosso ideário e nossas crenças e impregnam tanto as nossas células quanto nosso raciocínio, nosso vocabulário e nosso imaginário. Sem mencionar seu imenso papel na história das sociedades, hoje como ontem". (BOUGUERRA, 2003. p. 22)

A água se manifesta em todas as coisas, é o elemento mais comum sobre a Terra, formada pela combinação de dois componentes químicos, dois gases inodoros, incolores e insípidos, a proximidade com a natureza potencializa o sentimento pela água. "Melhor que qualquer outro, o homem do campo conhece o preço de uma água pura porque sabe que é uma pureza em perigo, porque sabe também beber a água clara e fresca no momento oportuno, nos raros instantes em que o insípido tem um sabor, em que o ser inteiro deseja a água pura" (BACHELARD, 1998).

O consumo aumenta a cada dia e os processos para tornar a água potável, assim como a distribuição, não acompanham a exigência, porém a consciência ambiental consiste também em reconhecer a água como direito fundamental, como patrimônio da humanidade e fonte de vida, 
manifestada na proteção dos corpos de água como garantia mínima, essencial à sadia qualidade de vida, o direito à água e o respeito à dignidade humana.

Perceber a Água como um bem, e não apenas como um recurso implica conhecê-la em seus aspectos simbólico, artístico, cultural e espiritual; as atitudes e ações de cuidado, proteção e gestão sustentável emergem não só do conhecimento intelectual, mas do sentimento presente no interior do ser humano; que conhecer e amar são passos que antecedem o valorizar e o cuidar; que o acima exposto requer mudanças fundamentais de valores, necessidades e modos de vida (CET-Água).

\section{Água Direito Existencial}

As mudanças ambientais ameaçam a sobrevivência dos seres humanos, dos milhares de outras espécies vivas, da integridade da Terra, da biodiversidade, da segurança das nações e das gerações futuras, as relações históricas e culturais ao longo dos tempos, produziram condições ambientais que apontam para a situação emergente insustentável da não garantia de água limpa para as gerações futuras, a água o patrimônio da humanidade, necessidade básica de todos os seres vivos, é direito inalienável dos seres humanos, ao negar água a alguém, nega-lhe também o direito à vida, A importância da água percebida como direito na cadeia vital, para a subsistência humana, possibilita as condutas com maior responsabilidade pelo uso.

Suprir de água potável a todos é considerado o maior e mais nobre dos objetivos da política pública, porém o grande erro é pensar que a solução deste problema está em economizar água - água parada apodrece, e água desperdiçada volta ao ciclo hidrológico. A água precisa é de cuidado, pois o problema mundial está na atitude de tudo ser depositado nela - nos rios, mares, lagoas enfim, nos corpos de água existentes sobre a superfície da Terra, a contaminação das águas cresce de forma assustadora, sendo a tarefa de tornar a água potável compromisso desafiador, a cada ano.

O planeta Terra possui $70 \%$ da superfície coberta por água, porém atualmente dezenas de milhares de pessoas vivem com menos de cinco litros de água por dia. Sabemos que a hidrosfera aproveitável é suficiente para a toda a população, porém é irregularmente distribuída, em algumas regiões torna-se recurso escasso. O Brasil tem posição privilegiada no cenário mundial das águas, resultado da extensão territorial e do ciclo hidrológico, influenciado pelo clima predominantemente equatorial e tropical úmido, possui $53 \%$ da água doce da América do Sul, e 12\% da vazão total mundial dos rios, ou seja, um total de 
$177,900 \mathrm{~m}^{3} / \mathrm{s}$, com precipitações médias anuais de 1.000 a $3.000 \mathrm{~mm} / \mathrm{ano}$ em mais de $90 \%$ do território.

TEIXEIRA, 2001. p.423, relata: “A abundância da água na região é o resultado da interação entre o clima e a fisiografia, sendo a relação entre a precipitação, evapotranspiração e as águas que circulam pelo planeta, através do escoamento superficial e subterrâneo. $\mathrm{O}$ excedente hídrico é a diferença entre volume precipitado e o evapotranspirado, ele pode ser decomposto no escoamento de água superficial e subterrânea".

A água, encontrada no planeta Terra, nos estados físicos sólido, gasoso e líquido e dentre os quais o mais importante é o líquido, pois neste, ela integra todos os processos naturais e produtivos, tendo o esgoto como produto, muitas vezes depositado nos cursos de água é cultura presente, perturbando as vidas aquáticas e contribuindo para onerar e dificultar o processo de renovação deste legado.

A saúde e o bem estar do ser humano estão intimamente ligados ao equilíbrio ecológico aquático, porém os diversos corpos de água responsáveis por tal equilíbrio, são afetados direta e diariamente por esgoto, poluindo, deteriorando e comprometendo o ciclo vital da água.

A demanda mundial por água dobra a cada 21 anos. Aproximadamente, $40 \%$ da população mundial não possui acesso a água limpa e 230 milhões de pessoas vivem em área de escassez hídrica. Mais de 2 milhões de pessoas não possuem saneamento básico adequado e a cada hora mais de 600 pessoas morrem por causa de água contaminada, imprópria para o consumo ou inexistente (AMORIM, 2009. p. 125)

Sendo a água o bem natural necessário ao desenvolvimento de diversas atividades humanas e grande número delas resultar em esgoto, seja ele, doméstico, industrial ou hospitalar, torna-se fator complexo, de preservação e uso, pois o esgoto deve ser minimizado, tratado, contabilizado para ser reintegrado de forma segura no ciclo hidrológico. O cuidado com a água só é efetivado a partir da compreensão da necessidade eminente do tratamento do esgoto e assim contribuir para a proteção e conservação da qualidade hídrica.

A causa principal da escassez da água doce, mundialmente, é o seu alto consumo pelos meios de produção. Seja diretamente através de sua apropriação como insumo, seja indiretamente através de sua contaminação pelas mais diversas fontes de poluição advindas dos processos produtivos humanos. (AMORIM, 2009 p. 127)

Os conflitos ambientais da atualidade como os desmatamentos, a degradação do solo, o uso e poluição da água entre outros, devem ser percebidos de forma integrada, e 
transdisciplinar onde usuário-poluidor emerge como sujeito de participação efetiva no direcionamento e tratamento dos resíduos, e corresponsável na contribuição com ideias e soluções para o desafio.

\section{Transdisciplinaridade, o Terceiro Incluído}

A ciência no decorrer da evolução humana até os dias atuais não tem dado conta de questões ambientais, pois a característica multifacetada da exploração insustentável dos recursos, torna necessária a mudança de paradigmas, assim como a proposição de novas formas de uso e exploração. A visão transdisciplinar é apresentada aqui como alternativa para elaboração de saberes e conhecimentos ambientais, utilizados como base para soluções em conflitos ambientais envolvendo a água e o ambiente.

O desafio é complexo, a necessidade é premente, e as soluções envolvem o entendimento da complexidade do uso da água, as diversas realidades existentes e o comprometimento do sujeito dependente como agente de preservação e conservação, contribuindo com ideias e soluções. "A visão transdisciplinar da Água inclui e excede a compreensão linear. Pressupõe um olhar abrangente sobre seus múltiplos aspectos e sua poderosa influência sobre tudo o que existe" (CET-Água).

O conhecimento básico do arcabouço histórico epistemológico sobre a interdisciplinaridade e transdisciplinaridade, torna-se importante para a compreensão e elaboração dos conhecimentos relativos ao objetivo deste artigo, isto é, analisar a relação transdisciplinar da água diante das interações desta com o mundo. Os conceitos da transdisciplinaridade surgiram nas décadas de 1960 e 1970, respectivamente e buscavam a superação da visão reducionista e fragmentada da natureza da realidade. "Naquela época predominava uma visão do real como se fosse algo estável, previsível, uniformemente ordenado, algo que deveria ser explicado, controlado e profetizado, capaz de gerar um conhecimento objetivo, disciplinar, neutro, simplificado e progressivo, livre dos valores subjetivos e dos contextos" (MORAES, 2008 p. 62).

Sem negar a interdisciplinaridade, a transdisciplinaridade está apoiada nela e vai além dela, os conceitos da interdisciplinaridade surgiram em 1961, nas ciências humanas. "[...] a partir de um projeto desenvolvido por Georges Gusdorf para a UNESCO, estava calcada em uma nova explicação da natureza do real e do conhecimento a partir de um novo paradigma 
científico voltado para a unicidade do conhecimento e da superação de sua natureza fragmentada ou desconectada" (MORAES, 2008 p. 62).

A ética transdisciplinar recusa toda atividade que evita o diálogo e a discussão, seja qual for sua origem - de ordem ideológica, científica, religiosa, econômica, política, ou filosófica (Nicolescu, 2000. p.7).

A transdisciplinaridade, porém não constitui termo novo, ele foi concebido por Jean Piaget em 1970, no I Seminário Internacional sobre pluri e interdisciplinaridade, em Nice, referindo que, àquela etapa deveria ser sucedida por uma transdisciplinar. Posteriormente no Colóquio "A Ciência diante das Fronteiras do Conhecimento" realizado de Veneza na Itália em 1986, a transdisciplinaridade é sugerida como método científico para a compreensão e apropriação humana dos diversos saberes, pois a produção acelerada e sem precedentes dos conhecimentos e a incapacidade da sociedade em fazer uso destes, atingiu o patamar onde põe em risco a existência humana e do planeta Terra (Declaração de Veneza).

Tendo a sustentabilidade como foco de toda ação humana, assim como toda produção de conhecimento deve objetivar a promoção da vida sobre a Terra, a transdisciplinaridade, não nega as práticas disciplinares, multidisciplinares e interdisciplinares, mas apoia-se nestas, como nova abordagem perceptiva sobre o objeto de estudo, analisando, refletindo e reelaborando os saberes diante do mundo presente. Nicolescu (2000. p. 139) define a prática da transdisciplinaridade como "encarnação de cada ação, da metodologia transdisciplinar, através de um conjunto de métodos adaptados a cada situação especifica".

Esta encarnação a princípio parece incompreensível, pois é difícil perceber algo nunca visto antes, pode parecer também, inatingível na plenitude, porém é necessária, a gradual mudança de atitude, assim como a percepção, que de forma gradativa, impregna as novas gerações, com noções de ecologia e, a abrangência deste conceito na interdependência do sujeito com a natureza.

Interdependência percebida em toda a manifestação humana que resulta em esgoto, contamina e polui as águas, interrompe o ciclo hidrológico natural, além de onerar, dificultar e prolongar o processo para torná-la potável. Parece difícil ao ser humano perceber o quanto é dependente deste bem, e o quanto ele precisa de cuidados, quanto mais poluímos, mais caro, ela (água) se torna.

A água lava tudo, parece ter dominado o pensamento dos usuários dependentes da água, sem levar em conta as consequências ambientais das próprias atividades insustentáveis 
praticadas. Tradicionalmente esgoto, lixo e efluentes industriais com frequência são lançados na água e o ambiente não consegue degradar e retornar ao equilíbrio natural, dizimando comunidades aquáticas e toda a cadeia do equilíbrio ecológico.

Assim a transdisciplinaridade oportuniza a compreensão e sensibilização do sujeito dependente como agente de proteção, preservação e conservação da água. Com maior envolvimento, incentivando a percepção contextualizada de mundo, onde a abordagem dos saberes, religioso, filosófico, científico e tradicional buscam a unidade do conhecimento dando sentido amplo às relações humanas com a água. "O eixo de compreensão da Transdisciplinaridade exige um olhar ampliado, rigoroso e inclusivo; reconhece a existência de diferentes níveis de realidade regidos por lógicas diversas; remete aos diferentes níveis de percepção do sujeito e aos diferentes níveis de realidade do objeto" (CET-Água).

Para compreender o conceito de terceiro incluído é necessário conhecer a relação epistemológica da concepção do termo. O romeno Stéphane Lupasco, nascido em 1900, idealiza a lógica do terceiro incluído, o elemento que vai além da dualidade prevista pelo princípio da identidade de Aristóteles, do ser ou não ser, (A - não A), isto é, introduzindo o terceiro elemento $\mathrm{T}$, e generalizou a lógica, incluindo física, epistemologia e a consciência.

Nicolescu, 2001. p. 110, refere, Lupasco não rejeita o princípio da identidade, apenas introduz este novo elementos às relações humanas com a natureza. " $\mathrm{O}$ famoso estado $\mathrm{T}(\mathrm{T}$ do "terceiro incluído") aparece pela primeira vez, na página 10 do Principe d'antagonisme. Ele é definido como um estado "nem atual nem potencial" e o terceiro incluído T - subjacentes ao princípio de antagonismo, sendo o terceiro unificador: ele une ser e não ser. Porém é necessário a compreensão dos níveis de realidade, termo proposto por Nicolescu em 1985, “[...] percebi subitamente que essa noção também dava uma explicação simples e clara da inclusão do terceiro. [...] A Realidade não é somente uma construção social, o consenso de uma coletividade, um acordo intersubjetivo. Ela é, também, uma dimensão transubjetiva, na medida em que um simples fato experimental pode arruinar a mais bela teoria científica".

Segundo Nicolescu (2000. p. 16), a transdisciplinaridade está apoiada em três pilares: os níveis de realidade, a complexidade e a lógica do terceiro incluído:

Traçado um paralelo entre os pilares de Nicolescu, o primeiro pilar está representado na ampla gama de relações da água na atualidade, a satisfação da imensa maioria das necessidades biológicas dos animais e vegetais como também os processos produtivos humanos, dependente da água, assim como o crescente aumento do uso promovido pelo 
desenvolvimento tecnológico e econômico, As diversas realidades a serem levadas em conta na formação e informação do cidadão dependente da água.

Os Niveis de Realidade - surgem no conhecimento da natureza, da sociedade e de nós mesmos, como estrutura complexa, cada nível é o que é porque todos os níveis existem simultaneamente, [...] relacionam-se com aquilo que é considerado ser "natural" e "social" e, por isso, é aplicável ao estudo da natureza e da sociedade Nicolescu (2000).

O segundo pilar da transdisciplinaridade é a complexidade traduzida na medida das relações encadeadas na sociedade, com a tecnologia, os diversos conhecimentos produzidos sobre a água, a dificuldade em lidar com as questões socioambientais, assim como o direito inalienável e a responsabilidade sobre este bem comum e intergeracional. A Complexidade, [...] ela é, portanto, produto de nossa cabeça, que é complexa por sua própria natureza. Porém esta complexidade é a imagem refletida da complexidade dos dados experimentais, que se acumulam sem parar. Ela também está, portanto, na natureza das coisas Nicolescu (2000).

Finalmente o último pilar, o terceiro incluído, aqui percebido na participação do sujeito dependente da água, transformando-se em agente de preservação e conservação, baseado na inseparabilidade do sujeito e objeto, isto é, na impossibilidade do usuário dissociar-se da carga de responsabilidade com a água, pelo uso e produto deste uso, contribuindo para a construção e elaboração de conhecimentos e tomando consciência da vital necessidade da água para a permanência da vida na Terra. "O terceiro pilar da transdisciplinaridade, o Terceiro Incluído, admite como o próprio termo diz, a inclusão do terceiro no processo, isto é o próprio indivíduo que constrói o conhecimento" (Nicolescu, 2000).

Na relação do sujeito dependente, quanto mais usa, mais a conhece como bem comum, mais é sensibilizado por ela e mais a protege; a água passa para o status de patrimônio das gerações atuais e futuras e toda a vida sobre a Terra é beneficiada, revertendo o produto do uso em benefício próprio (usuário) e das gerações futuras.

Sob a perspectiva da transformação social, trazer não só novos princípios, mas todo o entendimento diferenciado de pensar e agir, na oposição da prática ambiental insustentável e da velocidade sem precedentes da poluição e degradação da natureza, a definição de novos rumos para a as questões da água, no desenvolvimento sustentável, tem na figura do usuário o agente tomador de decisão, promovendo ações reflexivas e críticas, na elaboração de soluções racionais para tais questões. 
Enfatiza a sensibilização, as vivências práticas na relação do sujeito com o mundo, por múltiplas mediações sociais, onde a percepção ambiental, na busca por estimular a participação crítica dos envolvidos, com o entendimento diferenciado de pensar e agir, assim, dependente da formação e informação transformadora mobilizando os cidadãos para ações de interesse coletivo.

O ser humano posicionado no topo da racionalidade como ser pensante, atuando de forma crítica e reflexiva no exercício da cidadania, é sensibilizado a perceber a própria condição de terceiro incluído, elencado de forma crucial na interdependência da própria existência humana dependente da água comprometido em todo o processo hídrico natural.

A percepção transdisciplinar das relações estabelecidas com a água, na lógica do terceiro incluído, compromete os outros dois pilares, a complexidade e níveis de realidade, pois é impossível o envolvimento do sujeito dependente da água sem acrescentar a própria realidade ao processo, assim como a dialógica das relações remete dados de complexidade, quanto mais o sujeito usa a água mais se compromete, se envolve, preserva, conserva, cuida e é beneficiado por ela.

As inter-relações no processo transdisciplinar acontecem de forma gradativa, simultânea e difusa onde a participação efetiva do sujeito dependente traz consigo toda a complexidade das diversas realidades ambientais integrantes, desde a simbologia ao direito universal à água.

\section{CONCLUSÃO}

A transdisciplinaridade estimula a atuação crítica e reflexiva, do sujeito, usuário dependente da água, no processo permanente do uso e cuidado, na medida do entendimento das múltiplas mediações e da própria relação com o mundo, caracterizando-se como o terceiro incluído, atuando nos diversos papeis, na relação difusa e simultânea, da interação transdisciplinar, ora como usuário, ora como poluidor, ora como agente de proteção da água.

Para dar-se conta da complexidade do fato é necessário perceber as diversas "realidades" apresentadas, de forma justaposta, difusa e simultânea, assim como os sujeitos envolvidos; caso contrário estamos suscetíveis ao reducionismo, quando percebemos apenas a realidade, a física, imediata e unilateral. 
A apropriação da natureza, pelos seres humanos, utilizando-se dos bens por ela oferecidos, na produção e melhoria da qualidade de vida, tem, em contra partida o custo elevado do ambiente, colocando em risco a vida no planeta, promovendo transformações, modificando ecossistemas, cursos d'água e hábitats naturais de plantas e animais.

A água, foco principal da relação socioambiental e o elemento vital da existência humana neste planeta, ainda não conquistou seu lugar de destaque, pois é perceptível a incapacidade da sociedade, em lidar com a real situação deste bem, sem o conhecimento de que a água necessita de cuidado, muito mais que racionamento, sendo o ponto chave do conflito o comprometimento do sujeito dependente em todo o processo de uso e apropriação da água.

Assim, as atividades para a construção dos saberes relativos à água, de forma transdisciplinar, são capazes de evidenciar a complexidade das inter-relações e os níveis de realidade do sujeito e objeto, ou o usuário e a água, isto é possível na medida da compreensão e do comprometimento do indivíduo com a manutenção da própria vida, onde o sujeito dependente é o agente de preservação, desenvolvendo e mudando atitudes para o melhor uso da água.

A complexidade das relações da água nas mais diversas áreas do conhecimento e a inclusão do sujeito-dependente, como terceiro incluído, aumenta a responsabilidade conforme usa, quanto mais usa, mais se responsabiliza, preserva e conserva, no contexto da própria realidade e do mundo presente, revertendo em benefício próprio; as ações.

A ampla gama de situações cotidianas da manifestação humana dependente da água, assim como o crescente aumento do uso promovido pelo desenvolvimento tecnológico e econômico, retratam os diversos níveis de realidade a serem levados em conta na formação e informação do cidadão, usuário, sobre as questões da água.

A complexidade é traduzida na medida das relações travadas da sociedade, com os diversos conhecimentos sobre a água, a dificuldade em lidar com as questões socioambientais na preservação e conservação. Assim a gestão de recursos hídricos, pressupõe participação integrada e depende da formação transdisciplinar, pois a maneira fragmentada da disciplinaridade, não tem dado conta de mobilizar os cidadãos para ações de interesse coletivo, os usuários como promotores do conhecimento, com autoconfiança e resiliência para enfrentar e resolver problemas em sintonia com o ambiente, assumindo o papel essencial de agente de proteção, sujeito consciente da importância da água e da própria dependência deste 
bem comum, como o terceiro incluído, transformando-se em agente de preservação e conservação.

Para o reconhecimento da água como patrimônio vital global comum, é necessário sensibilizar as pessoas, por meio da percepção das diversas realidades e a complexidade envolvida, desde as relações simbólicas até a atual crescente demanda, sendo o cuidado, princípio a ser observado entre os seres humanos, Para tanto a transdisciplinaridade surge como característica inerente a água, percebida como ferramenta para formação e informação do cidadão, comprometendo-o de forma ampla, com as questões políticas e ambientais da atualidade que tendem a afetar a vida sobre a Terra.

No planejamento de cada atividade humana dependente da água é imprescindível a previsão de possíveis impactos causados ao ambiente, pois a água, elemento perene, após o uso, retorna a natureza e de forma apropriada deve ser integrada ao ciclo hidrológico, como reponsabilidade de todos que fazem uso dela.

Assim o aspecto relevante é a percepção da quantidade de poluição e contaminação despejadas nas águas, perturbando o ciclo hidrológico. A importância das matas ciliares, a recuperação e conservação, além da proteção de nascentes e pontos de recarga dos aquíferos.

A participação do usuário na adoção de ações e tecnologias voltadas para a preservação e conservação da água, na proteção e manejo ético dos corpos de água e as áreas de recarga, como garantia de acesso igualitário livre a todos, a água potável, inclusive aos que ainda não nasceram.

\section{BIBLIOGRAFIA ESPECÍFICA}

1. AMORIM, João Alberto Alves. Direito das águas. O Regime Jurídico da Água Doce no Direito Internacional e no Direito Brasileiro. Lex Editora S.A. São Paulo, 2009.

2. ANGUERA, Teresa et al, Transdisciplinaridade e ecoformação: Um novo olhar sobre a educação. Titulo original Transdisciplinariedad y Ecoformacion - Uma nueva mirada sobre la educacion. DE LA TORRE, Saturnino (direção) PUJOL, Maria Antonia; MORAES, Maria Candida. (coordenação) Suzana Vidigal. $1^{a}$ Ed. São Paulo: TRIOM, 2008. 432 p.

3. BACHELARD, Gaston. A Água e os Sonhos, Ensaio sobre a imaginação da matéria. Martins Fontes, São Paulo, 1998. Titulo original L'eau et les rêves. Trad. Antônio de Pádua Danesi. Rev. Rosemary Costhek Albino. Coord. Maurício Balthazar Leal; 206p. 
4. BOUGUERRA, Mohamed Larbi. As Batalhas da Água:Por um bem comum da humanidade. Titulo original em francês: Les batailles de l'eau - Pour um bien commun de l'humanitè, Petrópolis RJ: Vozes, 2004. 240 p.

5. BRASIL, Lei $\mathbf{N}^{0} \mathbf{9 . 4 3 3}$ de 8 de janeiro de 1997: Institui a Política de Recursos Hídricos, cria o Sistema Nacional de Gerenciamento de Recursos Hídricos, regulamenta o incisivo de XIX do art. 21 da Constituição Federal, e altera o art. $1^{\circ}$ da Lei $\mathrm{n}^{\circ}$ 8.001, de 13 de março de 1990, que modificou a Lei $\mathrm{n}^{\circ} 7.990$, de 28 de dezembro de 1989.

6. CET-Água. Carta Água e Transdisciplinaridade. Documento-síntese do $1^{\circ}$ Seminário Internacional Água e Transdisciplinaridade - para uma ecologia de saberes. Brasília/DF, 2011; 2p. $\quad$ http://cetagua.org/carta-de-principios-centro-deestudotransdisciplinar-da-agua-cet-agua/ acesso em 28.10.2012 as 17:47h

7. DOMINGUES, Ivan. Conhecimento e transdisciplinaridade II - Aspectos Metodológicos. Ivan Domingues org. Belo Horizonter: FMG, 2005. 424 p.

8. FLORES, Karen Müller. O Reconhecimento da Água como Direito Fundamental e suas implicações. RFD- Revista da Faculdade de Direito da UERJ, v.1, n. 19, jun./dez 2011.

9. FREITAS, Juarez. Sustentabilidade Direito ao futuro. $2^{\mathrm{a}}$ Ed. Belo Horizonte: Forum, 2012. $348 p$.

10. MONTANARI, Valdir. STRAZZACAPPA, Cristina. Pelos Caminhos da Água. $1^{\text {a }}$ Ed. São Paulo: Moderna, 1999. 56 p.

11. MORAES, Maria Candida, Interdisciplinaridade e Transdisciplinaridade na Educação, Fundamentos Ontológicos e Epistemológicos, Problemas e Práticas in: Transdisciplinaridade e ecoformação: Um novo olhar sobre a educação. Titulo original Transdisciplinariedad y Ecoformacion - Uma nueva mirada sobre la educacion. DE LA TORRE, Saturnino (direção) PUJOL, Maria Antonia; MORAES, Maria Candida. (coordenação) Suzana Vidigal. 1 Ed. São $^{a}$ Paulo: TRIOM, 2008. 432 p.

12. MORIN, Edgar. Introdução ao pensamento complexo. Trad. Eliane Lisboa. $4^{\mathrm{a}}$ Ed. Porto Alegre: Sulina, 2005. 120 p.

13. NICOLESCU, Basarab. Educação e transdisciplinaridade. Brasilia: UNESC, 2000. $188 \mathrm{p}$.

14. NICOLESCU, Basarab. BADESCU, Horia. Sthéphane Lupasco, O homem e a Obra. Título original Sthéphane Lupasco. Trad. Lucia Pereira de Souza. Revs. Vitória Mendonça de Barros e Ruth Cunha Cintra. São Paulo, TRIOM, 2001, 340p.

15. PALANIAPPAN, MEENA; et al.; Cuidandando das Águas: Soluções para melhorar a qualidade dos recursos hídricos; (Clearing the waters: a focus on wáter quality solutions); rev. Danúzia Queiroz; apres. Achim Steiner; trad. Agência Nacional de Águas (ANA) p. 158; 28 x 23 cm; 5 caps.;107 siglas; 230 refs.; 1 ilus.; 10 tabs.;9 
mapas.; 66 fotos; 125 sites; 4 gráfs.; no.; TDA; Brasília:ANA 2011; pags.:19 a 64; $160 \mathrm{p}$.

16. PETRELLA, Riccardo. O Manifesto da Água - Argumento para um contrato mundial. Título original - The water manifesto - Arguments for a world contract. Trad. Vera Lúcia Mello Joscelyne. Petrópolis, RJ: Vozes, 2002. 160 p.

17. PHILIPPI Jr, Arlindo at all, Interdisciplinaridade em Ciências Ambientais. São Paulo: Signus, 2000. 328p.

18. TEIXEIRA, Wilson. Decifrando a Terra. Organização de Wilson Teixeira ...et al. São Paulo: oficina de textos, 2001. 